\title{
CHARACTERISTICS AND ASSESSMENT OF THE HEAVY METAL CONTENT OF SOIL AND SPINACH WITH DIFFERENT REMEDIATION
}

\author{
WANG, N. $.^{1,2,3,4^{*}}-$ WEI, Y. ${ }^{1,2,3,4}-$ HE, L. R. ${ }^{1,2,3,4}-$ LI, G. ${ }^{1,2,3,4}-$ SUN, Y. Y. ${ }^{1,2,3,4}-$ LU, N. ${ }^{1,2,3,4}$ \\ ${ }^{1}$ Institute of Land Engineering and Technology, Shaanxi Provincial Land Engineering \\ Construction Group Co., Ltd., Xi'an 710075, China \\ ${ }^{2}$ Shaanxi Provincial Land Engineering Construction Group Co., Ltd., Xi'an 710075, China \\ ${ }^{3}$ Key Laboratory of Degraded and Unused Land Consolidation Engineering, the Ministry of \\ Natural Resources, Xi'an 710075, China \\ ${ }^{4}$ Shaanxi Provincial Land Consolidation Engineering Technology Research Center, Xi'an 710075, \\ China \\ ${ }^{*}$ Corresponding author \\ e-mail:Na0113@126.com; phone: +86-29-8662-5019
}

(Received 24 ${ }^{\text {th }}$ Jul 2020; accepted $19^{\text {th }}$ Nov 2020)

\begin{abstract}
In this study, we investigated the effects of different treatments on the physicochemical properties of heavy metal contaminated soil. The total amounts of $\mathrm{Hg}$, inorganic $\mathrm{As}, \mathrm{Pb}$, and $\mathrm{Cd}$ were determined in a soil-spinach system. The results show that for all of the groups, the soil $\mathrm{pH}$ increased by $0.16-1.10$, and the inorganic As content of the soil increased by $0.7-6.0 \mathrm{mg} / \mathrm{kg}$. The total content of $\mathrm{Hg}, \mathrm{Cd}$, and $\mathrm{Pb}$ in soil samples after T1-T7 decreased by $0.8-1.76 \mathrm{mg} / \mathrm{kg}, 8.0-17.1 \mathrm{mg} / \mathrm{kg}$, and $0.02-0.56 \mathrm{mg} / \mathrm{kg}$, respectively. The largest decreases in total $\mathrm{Hg}$ and $\mathrm{Cd}$, at $1.76 \mathrm{mg} / \mathrm{kg}$ and $0.93 \mathrm{mg} / \mathrm{kg}$, respectively were seen in group $\mathrm{T} 3$. Group T5 had the largest decrease in total Pb content, i.e., by $17.1 \mathrm{mg} / \mathrm{kg}$. After the T1-T7 treatments, the amount of $\mathrm{Hg}$, inorganic As, and $\mathrm{Cd}$ in the edible portion of the spinach exceed the National Food Safety Contaminant Limit (GB 2762-2012). However, the order of the risk index of the spinach after the seven treatments of restoration is $\mathrm{T} 1>\mathrm{T} 4>\mathrm{T} 6>\mathrm{T} 2>\mathrm{T} 3>\mathrm{T} 7>\mathrm{T} 5$. The risk index of treatment $\mathrm{T} 5$ is the lowest, which indicates that $3 \%$ cassava straw biochar is better than the other two biochar treatments.
\end{abstract}

Keywords: phytoremediation technology, soil-spinach, biochar, hazard index, potential ecological risk index

\section{Introduction}

Soil is the foundation of agricultural production, and it plays an essential role in the quality and safety of the agricultural product. Influenced by parent material (Zhuang et al., 2013; Waterlot et al., 2013), sewage irrigation (Hernandez-Soriano et al., 2012), mining (Wang et al., 2019), and other factors, different kinds of pollutants, especially heavy metals, enter the soil environment through the air, water, and other avenues. According to the 2014 Chinese National Soil Pollution Survey Bulletin, the overall soil environmental quality is not good. The overall standard rate of cultivated soil is $19.4 \%$, and the main pollution type is heavy metal pollution (MEP, 2014). However, due to the lack of arable land in China, the polluted soil is still used for food and other crop production (Xiao et al., 2017). Heavy metal pollution in the soil is highly toxic, persistent, and bioavailable. At present, heavy metal pollution in the soil has become a global problem (Li et al., 2014; Tóth et al., 2016). Compared to other pollutants, heavy metals can accumulate and migrate in the soil and destroy the functionality and balance of the soil ecosystem, seriously affecting human health (Lei et al., 2016) and causing food safety issues (Wuana et al., 
2011). Studies have shown that an excessive intake of $\mathrm{Pb}$ can damage the nervous system, the endocrine system, and the immune system (Zhang et al., 2012). When pregnant women are exposed to $\mathrm{Pb}$ pollution for a relatively long period of time, the $\mathrm{Pb}$ can be transferred from the skeleton of the mother to the body of the fetus at a faster rate, which not only causes certain obstacles to the neural development of the fetus but also affects its future life (Reuben et al., 2017). Long-term exposure to a Cd-polluted environment leads to the risk of lung cancer, renal insufficiency, fractures, and hypertension (Li et al., 2013). In addition, inorganic As is also highly toxic. The intake of large amounts of As strongly interferes with blood vessels and the central nervous system, and it can also lead to gene mutation. When the human body is exposed to As pollution for a long time, it is at risk of lung cancer (Järup, 2003). Compared with pesticides and other organic pollutants, heavy metal pollution has a long-term incubation nature, which undoubtedly increases the difficulty of treating soils that have been polluted with heavy metals. At present, the main methods of remediating heavy metal pollution in farmland include physical remediation, chemical remediation, biological remediation, engineering and technical measures, and agricultural ecological remediation. However, most of these remediation techniques are very expensive, so it is necessary to develop more cost-effective techniques that use lowcost adsorbents (Kailash et al., 2010). At present, the application of soil amendment and the optimization of soil nutrient management have become the most common remediation method. It is generally believed that biochar is the most effective adsorbent for the adsorption of heavy metals and organic pollutants in soil, and it can effectively improve the physical and chemical properties of the soil. In addition, the cost of biochar is relatively low (Klasson et al., 2014; Li et al., 2014).

Biochar is produced by the slow pyrolysis (usually $<700^{\circ} \mathrm{C}$ ) of biological residues in a hypoxic environment (Lehmann and Joseph, 2015). Biochar is a type of insoluble, stable, highly aromatic, and carbon-rich solid substance (Titirici et al., 2007; Tang et al., 2013). The main elements of biochar are carbon, hydrogen, and oxygen, but it is highly enriched in carbon (70\%-80\%). Biochar is made from a wide range of raw materials, mainly including agricultural and forestry waste, such as wood, straw, fruit shell, organic waste generated by industry, and other urban life waste, such as garbage and sludge (Brick et al., 2010; Chen et al., 2010; Cantrell et al., 2012; Enders et al., 2012). Biochar has a large specific surface area, pore structure, and abundant surface functional groups, which can reduce the bioavailability of heavy metals in soil (Pan et al., 2014). Biochar also improves the activity of soil microorganisms, thus increasing the decomposition and deactivation of harmful substances (Baiamonte et al., 2015; Liu et al., 2016; Abujabhah et al., 2016). Biochar not only has a significant impact on the mitigation of heavy metals in soil, but also directly absorbs the heavy metal ions in the soil, reducing the toxicity of the polluted soils and reducing the toxicity of the plants. In addition, biochar is used in soil improvement (Tang et al., 2013), crop yield increase (Glaser et al., 2002), greenhouse gas emission reduction (Van Zwieten et al., 2009; Woolf et al., 2010; Singh et al., 2012), and the remediation of polluted environments (Sun et al., 2011). Therefore, it has broad application prospects. In recent years, the adsorption of heavy metals by biochar has attracted a great deal of attention, especially in the treatment of heavy metals in sewage (Ahmad et al., 2014; Komkiene et al., 2016) and the remediation of heavy metal contaminated soil (Hossain et al., 2010). For example, Choppala et al. (2012) and others demonstrated that biochar can transform $\mathrm{Cr}^{6+}$ into $\mathrm{Cr}^{3+}$, thus reducing the toxicity of $\mathrm{Cr}$. Houben et al. (2013) and others found that the addition of $10 \%$ biochar significantly reduces the extractable $\mathrm{Cd}, \mathrm{Zn}$, and $\mathrm{Pb}$ content of heavy metal contaminated soil by $71 \%$, 
$87 \%$, and $92 \%$, respectively. Bian et al. (2014) determined that the application of crop straw biochar to paddy soil polluted by heavy metals significantly reduced the absorption of $\mathrm{Cd}$ by rice. $\mathrm{Lu}$ et al. (2014) found that straw biochar can effectively reduce the concentrations of $\mathrm{Cu}$ and $\mathrm{Pb}$ in aboveground crops, and bamboo biochar can effectively reduce the concentration of $\mathrm{Cd}$ in soil. We believe that the influence of biochar on heavy metals is related to not only the raw materials from which the biochar is made and the amount applied to the soil but also the type of heavy metals. This study shows that biochar can effectively reduce the plant availability and ecological toxicity of heavy metals such as $\mathrm{Cd}$ and $\mathrm{Pb}$, and it provides a theoretical basis for the remediation of soil contaminated by heavy metals.

In view of the rapid development of agriculture in China, the production of crop straw is also increasing. However, the common practice in China is to burn the straw remaining in the fields after harvest. According to statistics, the total annual output of crop straw in China is more than $6 \times 10^{8}$ tons, among which the outputs of rice, wheat, and corn straw are about $1.1 \times 10^{8}, 1.3 \times 10^{8}$, and $2.3 \times 10^{8}$ tons, respectively. At present, $25 \%$ of crop straw is burned in the open air after the harvest to remove this crop residue (Shi et al., 2014), of which the smoke is harmful to the air quality and human health (Shen et al., 2016). Therefore, it is necessary to find a new method of crop straw utilization. It is cost-effective to use agricultural plant residues as biochar production materials, making it a renewable waste (Nuithitikul et al., 2010). Cassava, rice, and reed straw are the main agricultural waste plant fibers in China. The preparation of biochar based on this material not only fully utilizes the waste resources but also benefits the environment. Previous studies have focused on the remediation effect of a single type of biochar on heavy metals in soil. In this study, different percentages of cassava straw, rice straw, and reed straw biochar were added to heavy metal contaminated soil. The adsorption efficiency and effectiveness of these three types of biochar on the heavy metals were compared. This study can provide supporting data for the improvement of the resource utilization of crop straw and remediation of heavy metal pollution.

\section{Materials and Methods}

\section{Test material}

The raw materials used in this study were produced by rice straw, cassava straw and reed straw. The biochar sample used in the study was collected in the region of Fupin County. All the biochar used for the tests were prepared using the temperature control method with an oxygen limiting program. First, the cassava stems, rice stems, and reed stems were washed with clean water and allowed to dry naturally. Second, the air-dried and chopped raw materials were placed into closed iron containers. Each container was filled with $\mathrm{N}_{2}$ for $10 \mathrm{~min}$, the air was emptied, and they were heated in a preheated muffle furnace with limited oxygen. Finally, the muffle furnace was set to $500^{\circ} \mathrm{C}$ for $4 \mathrm{~h}$. The closed muffle furnace was allowed to naturally cool to room temperature, and the samples were removed and ground to 100 mesh. The basic properties of the biochar materials are shown in Table 1.

The soil used in the tests was collected from the $\mathrm{Hg}$ mine in Ankang City, Xunyang County. The soil collected was all 0-20 cm topsoil, which was air-dried in a cool place and sieved through a 5-mm sieve. 
Table 1. Basic physicochemical properties of the materials used in the experiments

\begin{tabular}{c|c|c|c}
\hline Tested materials & Reed biochar & Cassava biochar & Rice biochar \\
\hline $\mathrm{pH}$ & 10.6 & 11.2 & 10.9 \\
Organic matter $(\%)$ & 51 & 64 & 57 \\
Conductivity $(\mu \mathrm{S} / \mathrm{cm})$ & 677 & 1313 & 911 \\
Organic carbon $(\mathrm{g} / \mathrm{kg})$ & 392.34 & 591.22 & 658.21 \\
Ash $(\%)$ & 15.75 & 9.85 & 40.00 \\
$\mathrm{C} / \mathrm{N}$ & 85.07 & 42.13 & 30.15 \\
$\mathrm{C} / \mathrm{H}$ & 37.55 & 39.97 & 36.77 \\
\hline
\end{tabular}

Note: The values in the table are presented as average values

Biochar SEM images were obtained by FEI Q45 scanning electron microscop (FEI, USA). A CHN elemental analyzer (Flash EA 1112, Thermo Finnigan) was used to determine the carbon $(\mathrm{C})$, hydrogen $(\mathrm{H})$, and nitrogen $(\mathrm{N})$ contents of all biochars.

The $\mathrm{pH}$ of the biochar and soil were measured in a 1:10 ratio of biochar suspension in deionized water. The concentrations of $\mathrm{Hg}$ and inorganic As were digested by $\mathrm{HNO}_{3}-\mathrm{H}_{2} \mathrm{SO}_{4}$, after that, atomic fluorescence Spectrometry (AFS-9760) at $253.65 \mathrm{~nm}$ was used for the measurement. The concentration of $\mathrm{Cd}$ and $\mathrm{Pb}$ were digested by $\mathrm{HNO}_{3}-\mathrm{H}_{2} \mathrm{O}_{2}-\mathrm{HCl}$ with the ratio of 3:1 (hydrochloric and nitric acids), then using ICPMS (Agilent 7700e, USA) for their measurement.

In the experiment, 20\% parallel samples, GSS9-16 and GSB-26 were used for quality control, and the error was controlled within 5\%. The reagents were of excellent grade and the test vessels were soaked in $10 \%$ nitric acid for more than $24 \mathrm{~h}$ before use.

\section{Design of experiment}

The spinach was planted in the temperature room of Qinling field monitoring center, and the indoor temperature range was $23 \sim 28^{\circ} \mathrm{C}$. Each basin $(18.0 \mathrm{~cm}$ in height, 20.0 $\mathrm{cm}$ in diameter, and 13.0 in bottom diameter) was filled with $3 \mathrm{~kg}$ of soil, and a tray was arranged at the bottom of the basin to prevent the leakage of soil and water. Biochar of a certain quality was applied and mixed with the soil according to the experimental design (Table 2). The soil water content was more than $60 \%$ of the field water capacity throughout the growth period of the spinach. After 30 days of stabilization, the seeds were planted in the plastic basin in May of 2019, three parallel groups were setup for each remediation method. When the spinach trilobal stage, the seedlings were interspecific to 3 plants.

Table 2. Test design for the different biochar treatments

\begin{tabular}{c|c}
\hline Treatments & Specific operation procedures \\
\hline T1 & The control group. No heavy metal reduction \\
T2 & measures were taken. \\
T3 & $1 \%$ reed biochar added \\
T4 & $3 \%$ reed biochar added \\
T5 & $1 \%$ cassava biochar added \\
T6 & $3 \%$ cassava biochar added \\
T7 & $1 \%$ rice biochar added \\
\hline
\end{tabular}


After about 45 days later, soil samples and plant samples were collected, after natural air drying, $50 \mathrm{~g}$ of soil samples were ground and passed through nylon screen by quartering method. The upper part of plant samples was collected, washed with tap water, then repeatedly washed with deionized water. After being killed at $105^{\circ} \mathrm{C}$ for 0.5 $\mathrm{h}$, dried at $75^{\circ} \mathrm{C}$ to constant weight, the soil samples were crushed, passed through 60 mesh nylon screen and bagged for standby.

\section{Data analysis method}

SPSS 20.0 was used for statistical analysis, one-way ANOVA was used to compare the treatment, Duncan method was used to analyze the difference significance, and Excel 2010 and sigmaplot 10.0 were used to create the plots. The potential ecological risk index was used to evaluate the soil, and the risk index was used to evaluate the heavy metal content in the spinach.

\section{Evaluation method}

\section{Potential ecological risk index method}

The potential ecological risk index method was proposed by Swedish scientist Hakanson in 1980. Because it considers the toxicity differences of the different heavy metals and the sensitivity of the environment to heavy metal pollution, this method more accurately expresses the impact of heavy metals on the ecological environment. The calculation equations are as follows:

$$
\begin{gathered}
C_{f}^{i}=\frac{c_{s}^{i}}{c_{n}^{i}} \\
E_{r}^{i}=T_{r}^{i} \times C_{f}^{i} \\
R I=\sum_{i=1}^{n} E_{r}^{i}
\end{gathered}
$$

In these equations, $C_{s}^{i}$ is the measured value of the sample $(\mathrm{mg} / \mathrm{kg}) ; \mathrm{C}_{\mathrm{n}}^{\mathrm{i}}$ is the soil background value of Shaanxi Province $(\mathrm{mg} / \mathrm{kg}) ; \mathrm{T}_{\mathrm{r}}^{\mathrm{i}}$ is the toxicity response coefficient of the $\mathrm{i}$-th heavy metal; $\mathrm{E}_{\mathrm{r}}^{\mathrm{i}}$ is the potential ecological risk factor of the $\mathrm{i}$-th heavy metal; $\mathrm{RI}$ is the potential ecological risk index of the pollutant; and $\mathrm{C}_{\mathrm{f}}^{\mathrm{i}}$ is the pollution coefficient of the $\mathrm{i}$-th heavy metal. The classification of the potential ecological risks is shown in Table 3.

\section{Hazard index method}

The hazardous impact of heavy metals on human health is the result of a combination of various elements. Therefore, the hazard index (HI) used to conduct a comprehensive evaluation of the health risk of heavy metals to the human body. The calculation equation is as follows: 


$$
H I=\sum_{i=1}^{4} H Q
$$

Table 3. Potential ecological risk assessment and corresponding pollution degree

\begin{tabular}{cc|cc}
\hline \multicolumn{2}{c|}{ Potential ecological risk factors, $\mathbf{E}_{\mathbf{r}}^{\mathbf{i}}$} & \multicolumn{2}{c}{ Potential ecological risk index, RI } \\
\hline $\begin{array}{ccc}\text { Single heavy metal } \\
\text { threshold interval }\end{array}$ & Risk factor classification & $\begin{array}{c}\text { Threshold range for } \\
\text { multiple metals }\end{array}$ & Risk index classification \\
$(-\infty, 40)$ & A, Slight ecological harm & $(-\infty, 150)$ & $1 \downarrow^{*}$ ROMAN No risk \\
{$[40,80)$} & B, Moderate ecological damage & {$[150,300)$} & $2 \downarrow^{*}$ ROMAN Mild risk \\
{$[80,160)$} & C, Strong ecological harm & {$[300,600)$} & $3 \downarrow^{*}$ ROMAN moderate risk \\
{$[160,320)$} & D, Very strong ecological harm & {$[600,+\infty)$} & $4 \downarrow^{*}$ ROMAN Serious risk \\
{$[320,+\infty)$} & E, Extreme ecological harm & -- & - \\
\hline
\end{tabular}

In Eq.(4), HQ is the health value of a single heavy metal. If $\mathrm{HI} \in(-\infty, 1.0]$, the heavy metals have no negative impact on human health; if $\mathrm{HI} \in(1.0,10)$, the heavy metals may have a relatively negative impact on human health; and if $\mathrm{HI} \in[10,+\infty)$, the heavy metals have a toxic impact on human health.

$$
H Q_{i}=\frac{C I D_{i}}{R f D_{i}}
$$

In Eq.(5), $\mathrm{CID}_{\mathrm{i}}$ is the daily intake of the heavy metal $\mathrm{i}(\mathrm{mg} / \mathrm{kg} \cdot \mathrm{d})$, and $\mathrm{RfD}_{\mathrm{i}}$ is the oral dose of heavy metal i $(\mathrm{mg} / \mathrm{kg} \cdot \mathrm{d})$. According to the EPA health risk model of the United States, the oral reference doses of $\mathrm{Hg}, \mathrm{As}, \mathrm{Pb}$, and $\mathrm{Cd}$ are 0.0003, 0.0003, 0.004, and $0.001 \mathrm{mg} / \mathrm{kg} \cdot \mathrm{d}$, respectively.

$$
C I D_{i}=\frac{C_{i} \times I R \times E F \times E D}{B W \times A T}
$$

In Eq.(6), $\mathrm{C}_{\mathrm{i}}$ is the content of heavy metal $\mathrm{i}$ in the edible part of the spinach $(\mathrm{mg} / \mathrm{kg})$; IR is the average daily meal of adults, $0.389 \mathrm{~kg}$ (person $\cdot \mathrm{d}$ ); $\mathrm{EF}$ is the exposure frequency, $350 \mathrm{~d} / \mathrm{a}$; ED is the lifetime exposure time, we use $65 \mathrm{a}$; BW is the average weight of an adult, $62.7 \mathrm{~kg}$; and the life expectancy in days is $65 \times 365 \mathrm{~d}$.

\section{Results and Analysis}

\section{Surface characteristics of the biochar}

Figure 1 shows picture from a scanning electron microscope of the three types of biochar. As can be seen in Figure 1, there are differences among the apparent morphologies of the three types of biochar, which is due to the natural differences in the tissue morphology of the different plants. All three types of biochar have porous structures and large specific surface areas. The biochar of the reed pole is relatively smoother, with some long and narrow filaments and noticeable surface gullies. The structure of the cassava biochar is clear and honeycombed, and the number of 
micropores is greater than those of the other biochar. The surface of the rice biochar is rough, and there are many small particles on the surface. The results show that the average pore size of the cassava biochar is $12.08 \mu \mathrm{m}$, followed by rice biochar $(4.26 \mu \mathrm{m})$ and reed biochar $(2.53 \mu \mathrm{m})$.

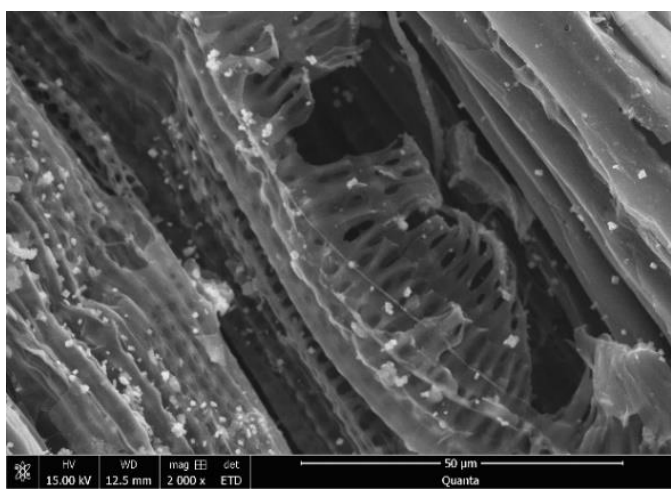

Reed stalk biochar

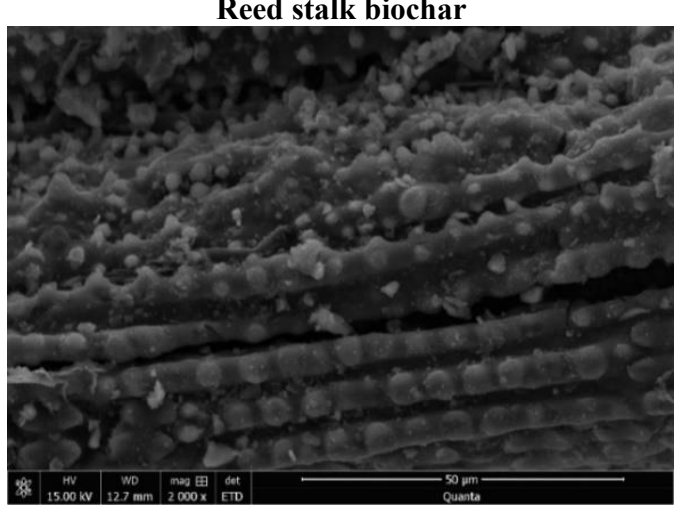

Rice stalk biochar

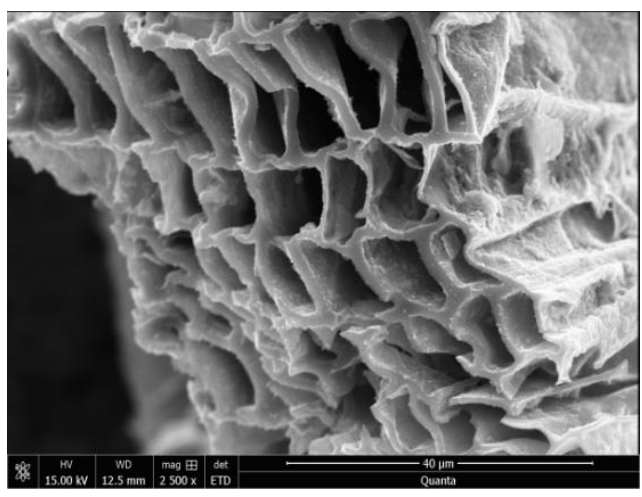

Cassava stalk biochar

Figure 1. SEM images of the biochar surfaces

\section{Analysis and evaluation of the physical and chemical properties and heavy metal content of unrepaired soil}

The assessment results of the potential ecological risk factors revealed that the $\mathrm{Pb}$ and $\mathrm{Cd}$ pollution levels of the soil from the sampling point is level $\mathrm{A}$, i.e., it caused slight harm to the ecological soil environment. The pollution level of inorganic As in the soil is level $\mathrm{B}$, i.e., an intermediate degree of ecological harm; and the $\mathrm{Hg}$ pollution level of the soil is level E, i.e., it is very harmful to the ecological soil environment. The potential ecological $\mathrm{RI}$ of $\mathrm{Hg}, \mathrm{Cd}$, As, and $\mathrm{Pb}$ was 2901.59, indicating a serious degree of risk (Table 4).

\section{Changes in the organic matter and $\mathrm{pH}$ of soil after biochar treatment}

The effects of treatments $\mathrm{T} 1-\mathrm{T} 7$ on soil $\mathrm{pH}$ and the organic matter are shown in Figure 2. As can be seen in Figure 2, the $\mathrm{pH}$ and organic matter in the soil changed after each treatment. The $\mathrm{pH}$ range of the soil before treatment was 6.33-8.46; after the T1-T7 treatments were applied, the $\mathrm{pH}$ value of soil increased by $0.16-1.10$. The soil organic matter (SOM) content before the treatments were applied ranged from 33.126 to $65.332 \mathrm{~g} / \mathrm{kg}$ and the change in the SOM content caused by the treatments ranged 
from 31.218 to $63.023 \mathrm{~g} / \mathrm{kg}$. Specifically, after treatments T2, T6, and T7 were applied, the SOM content increased by $2.10,1.92$, and $2.64 \mathrm{~g} / \mathrm{kg}$, respectively; however, for $\mathrm{T} 1$, T3, T4, and T5, the SOM content decreased after treatment by 1.91, 2.75, 1.60, and $3.91 \mathrm{~g} / \mathrm{kg}$, respectively. The above results show that the $\mathrm{pH}$ and organic matter content of the soil changed after the different treatments were applied, but no pattern was revealed in these changes. This could be because the physical and chemical properties of the soil are affected by a variety of factors such as the test temperature and microbial activity.

Table 4. Evaluation of the heavy metal content of the unamended soil

\begin{tabular}{c|c|c|c|c}
\hline \multirow{2}{*}{ Item measured } & \multirow{2}{*}{ Average value } & \multirow{2}{*}{ Standard value } & \multicolumn{2}{|c}{$\mathbf{E}_{\mathrm{r}}^{\mathrm{i}}$} \\
\cline { 4 - 5 } & & & Numerical value & Pollution class \\
\hline $\mathrm{Hg}(\mathrm{mg} / \mathrm{kg})$ & $5.14 \pm 1.35$ & 2.4 & 2901.59 & $\mathrm{E}$ \\
Inorganic As (mg/kg) & $75.71 \pm 2.76$ & 30 & 68.21 & $\mathrm{~B}$ \\
$\mathrm{~Pb}(\mathrm{mg} / \mathrm{kg})$ & $94.33 \pm 2.69$ & 120 & 22.04 & $\mathrm{~A}$ \\
$\mathrm{Cd}(\mathrm{mg} / \mathrm{kg})$ & $0.73 \pm 0.33$ & 0.3 & 28.82 & $\mathrm{~A}$ \\
$\mathrm{pH}$ & $6.71 \pm 0.85$ & -- & -- & -- \\
Organic matter (g/kg) & $2.86 \pm 0.56$ & -- & -- & -- \\
Cation exchange capacity & $15.96 \pm 0.99$ & -- & -- & $\mathrm{IV}$ \\
(cmol/kg) & -- & -- & 3014.66 & \\
$\mathrm{RI}$ & & &
\end{tabular}
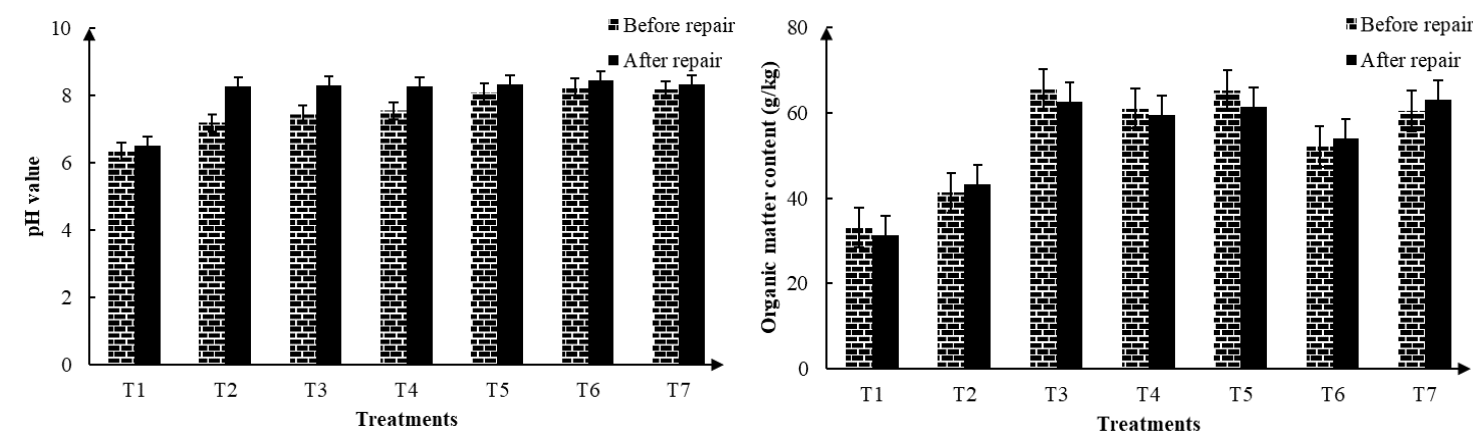

Figure 2. Changes in the $\mathrm{pH}$ value and organic matter content of the soil before and after the different treatments were applied, Error bars represent standard deviation $(n=3)$. The same as below

\section{Detection and evaluation of the heavy metal content in soil after the different biochar treatments}

\section{Characteristics and evaluation of the total $\mathrm{Hg}$ content of the soil}

The effects of the different remediation treatments on the total $\mathrm{Hg}$ content of the soil are shown in Table 5. As can be seen in Table 5, there is a certain difference in the total $\mathrm{Hg}$ content of the soil after treatments $\mathrm{T} 1-\mathrm{T} 7$. Compared with $\mathrm{T} 1$, the total $\mathrm{Hg}$ content in T2-T7 decreased by $0.97-2.29 \mathrm{mg} / \mathrm{kg}$, and the largest reduction was seen in T3. The results show that the effect of the reed biochar on the total $\mathrm{Hg}$ content was the best, and the higher the amount of reed biochar, the stronger its repairing ability. The potential ecological risk assessment index shows that the pollution level of the total $\mathrm{Hg}$ content of the soil after treatments T1-T7 were applied was level E. Although the total $\mathrm{Hg}$ 
content of the soil was lower after treatments T1-T7, it was still high enough to cause serious harm to the ecological soil environment.

Table 5. Hg content of soil and evaluation of the different treatments $(N=3)$

\begin{tabular}{c|c|c|c}
\hline \multirow{2}{*}{ Repair treatments } & \multirow{2}{*}{ Mean } & \multicolumn{2}{|c}{$\mathbf{E}_{\mathrm{r}}^{\mathbf{i}}$} \\
\cline { 3 - 4 } & & Value & Pollution level \\
\hline T1 & $5.89 \pm 0.19$ & 3739.68 & $\mathrm{E}$ \\
T2 & $4.92 \pm 0.64$ & 3121.69 & $\mathrm{E}$ \\
T3 & $3.60 \pm 0.44$ & 2285.71 & $\mathrm{E}$ \\
T4 & $3.89 \pm 0.46$ & 2467.72 & $\mathrm{E}$ \\
T5 & $3.85 \pm 0.49$ & 2442.33 & $\mathrm{E}$ \\
T6 & $4.22 \pm 0.63$ & 2679.37 & $\mathrm{E}$ \\
T7 & $3.62 \pm 0.49$ & 2296.30 & $\mathrm{E}$ \\
\hline
\end{tabular}

Note: Every treatment has three parallel (The same as below)

Characteristics and evaluation of the inorganic As content of the soil

The effects of the different remediation treatments on the inorganic As content of the soil are shown in Table 6. As can be seen in Table 6, compared with T1, after remediation treatments $\mathrm{T} 2-\mathrm{T} 7$ were applied, the inorganic As content of the soil decreased by $0.6-9.8 \mathrm{mg} / \mathrm{kg}$. Among all of the remediation treatments, the inorganic As content of the soil decreased the most after method T3 was applied, with a value of 9.8 $\mathrm{mg} / \mathrm{kg}$. The results show that the effect of reed stalk biochar was better than that of the other two materials, and the higher the amount of reed stalk biochar, the better the effect of the remediation. The potential ecological risk assessment index shows that the inorganic As pollution level in the soil after treatments T2 and T3 were applied was level A, i.e., it still causes a slight degree of ecological risk. After treatments T1 and T4-T7 were applied, the pollution level of the inorganic As in the soil was level B. Although the inorganic As content decreased, it still resulted in a moderate degree of harm to the ecological environment.

Table 6. Inorganic As content and evaluation of the soil after different treatments $(N=3)$

\begin{tabular}{c|c|c|c}
\hline \multirow{2}{*}{ Treatment } & \multirow{2}{*}{ Mean } & \multicolumn{2}{|c}{$\mathbf{E}_{\mathrm{r}}^{\mathrm{i}}$} \\
\cline { 3 - 4 } & & Value & Pollution level \\
\hline T1 & $49.0 \pm 3.68$ & 44.14 & $\mathrm{~B}$ \\
T2 & $43.2 \pm 2.37$ & 38.89 & $\mathrm{~A}$ \\
T3 & $39.2 \pm 3.12$ & 35.32 & $\mathrm{~A}$ \\
T4 & $46.7 \pm 3.41$ & 42.07 & $\mathrm{~B}$ \\
T5 & $48.4 \pm 1.94$ & 43.63 & $\mathrm{~B}$ \\
T6 & $47.2 \pm 2.16$ & 42.49 & $\mathrm{~B}$ \\
T7 & $45.3 \pm 3.27$ & 40.84 & \\
\hline
\end{tabular}

\section{Characteristics and evaluation of the total Pb content of the soil}

The total $\mathrm{Pb}$ contents of the soil after treatments $\mathrm{T} 1-\mathrm{T} 7$ were applied are shown in Table 7. As can be seen in Table 7, there is a difference in the total $\mathrm{Pb}$ content of the soil after treatments T1-T7 were applied. Compared with method T1, after treatments $\mathrm{T} 2-\mathrm{T} 7$ were applied, the total $\mathrm{Pb}$ content of the soil decreased by $10.8-24.1 \mathrm{mg} / \mathrm{kg}$, and 
the total $\mathrm{Pb}$ content of the soil after T3 was applied decreased by $24.1 \mathrm{mg} / \mathrm{kg}$. The effect of $\mathrm{T} 3$ on the recovery of $\mathrm{Pb}$ from the soil was better than those of the other treatments, and the higher the content of biochar used, the better the recovery effect. The potential ecological risk index shows that the pollution level of the total $\mathrm{Pb}$ in the soil after treatments T1-T7 were applied was level A. Although the total Pb content of the soil after treatments T1-T7 were applied was lower, it was still high enough to cause a slight amount of harm to the ecological soil environment.

Table 7. Pb content and evaluation of soil after different treatments $(N=3)$

\begin{tabular}{c|c|c|c}
\hline \multirow{2}{*}{ Treatment } & \multirow{2}{*}{ Mean } & Value & $\mathbf{E}_{\mathrm{r}}^{\mathrm{i}}$ \\
\cline { 2 - 4 } & & 19.30 & $\mathrm{Pollution}$ level \\
\hline T1 & $82.6 \pm 13.76$ & 14.74 & $\mathrm{~A}$ \\
$\mathrm{~T} 2$ & $63.1 \pm 8.31$ & 13.66 & $\mathrm{~A}$ \\
$\mathrm{~T} 3$ & $58.5 \pm 5.99$ & 15.11 & $\mathrm{~A}$ \\
T4 & $64.7 \pm 3.09$ & 16.77 & $\mathrm{~A}$ \\
T5 & $71.8 \pm 3.67$ & 14.82 & $\mathrm{~A}$ \\
T6 & $63.4 \pm 8.49$ & 15.13 & $\mathrm{~A}$ \\
T7 & $64.8 \pm 3.02$ &
\end{tabular}

\section{Characteristics and evaluation of the total Cd content of the soil}

The total Cd content of the soil after treatments T1-T7 were applied is shown in Table 8. As can be seen in Table 8, compared with method T1, after treatments T2 and T5 were applied, the Cd content of the soil increased by 0.08 and $0.15 \mathrm{mg} / \mathrm{kg}$, respectively. After treatments T3, T4, and T6 were applied, the Cd content of the soil decreased by $0.20,0.13$, and $0.07 \mathrm{mg} / \mathrm{kg}$, respectively, and the total $\mathrm{Cd}$ content of the soil after method T6 was applied decreased more than those of treatments T3 and T4. In general, the remediation effect of each treatment on the $\mathrm{Cd}$ in the soil was not significant. The potential ecological risk index shows that the pollution level of the total $\mathrm{Cd}$ in the soil after treatments T2 and T5 was level B, i.e., a medium degree of harm to the ecological soil environment. The pollution level of the total $\mathrm{Cd}$ in the soil after the other remediation treatments was level A. Although the total Cd content of the soil was low, it was still high enough to cause a slight amount of harm to the ecological soil environment.

Table 8. Cd content and evaluation of the different repaired soils $(N=3)$

\begin{tabular}{c|c|c|c}
\hline \multirow{2}{*}{ Treatment } & \multirow{2}{*}{ Mean } & Value & Pollution levels \\
\cline { 2 - 4 } & & 38.68 & $\mathrm{~A}$ \\
T1 & $0.98 \pm 0.09$ & 41.97 & $\mathrm{~B}$ \\
T2 & $1.06 \pm 0.41$ & 30.79 & $\mathrm{~A}$ \\
T3 & $0.78 \pm 0.09$ & 33.42 & $\mathrm{~A}$ \\
T4 & $0.85 \pm 0.05$ & 44.74 & $\mathrm{~B}$ \\
T5 & $1.13 \pm 0.05$ & 36.05 & $\mathrm{~A}$ \\
T6 & $0.91 \pm 0.05$ & 38.68 & $\mathrm{~A}$ \\
T7 & $0.98 \pm 0.07$ & & \\
\hline
\end{tabular}


Changes in the $\mathrm{Hg}, \mathrm{Pb}, \mathrm{Cd}$ and inorganic As content of the soil before and after treatment

Comparisons of the total $\mathrm{Hg}, \mathrm{Pb}, \mathrm{Cd}$ and inorganic As content of the soil before and after the treatments were applied are shown in Figure 3. As can be seen in Figure 3, the total $\mathrm{Hg}, \mathrm{Pb}$, and $\mathrm{Cd}$ content of the soil after treatments $\mathrm{T} 1-\mathrm{T} 7$ were applied are lower than those before treatment, with decreases of $0.8-1.76 \mathrm{mg} / \mathrm{kg}, 8.0-17.1 \mathrm{mg} / \mathrm{kg}$, and $0.02-0.56 \mathrm{mg} / \mathrm{kg}$, respectively. Among all of the groups, the total $\mathrm{Hg}$ and $\mathrm{Cd}$ content of the soil after T3 was applied show the most improvement, with a decrease of 1.76 $\mathrm{mg} / \mathrm{kg}$ and $0.93 \mathrm{mg} / \mathrm{kg}$, respectively. After T5 was applied, the total $\mathrm{Pb}$ content of the soil decreased the most $(17.1 \mathrm{mg} / \mathrm{kg})$. According to the comparison of the specific operation procedures for treatments T1-T7 (Table 2), T3 involves the addition of 3\% reed biochar, and T5 involves the addition of 3\% cassava biochar. Thus, it can be concluded that the addition of $3 \%$ reed biochar has a better effect on reducing the total $\mathrm{Hg}$ and $\mathrm{Cd}$ content of the soil. The addition of $3 \%$ cassava biochar can reduce the total $\mathrm{Pb}$ in soil. In addition, the inorganic As content of the soil after remediation treatments T2-T7 were applied increased by $0.7-6.0 \mathrm{mg} / \mathrm{kg}$ compared with the amounts before remediation. Combined with the results of previous studies (Wei et al., 2016), the $\mathrm{pH}$ value in the soil has a significant influence on the effectiveness of available As in the soil. In an acidic environment, the inorganic As in the soil exists in the form of $\mathrm{H}_{3} \mathrm{AsO}_{3}$. With increasing $\mathrm{pH}$, the inorganic As in the soil is released in the form of dissociation at all levels, which increases the inorganic As content of the soil.
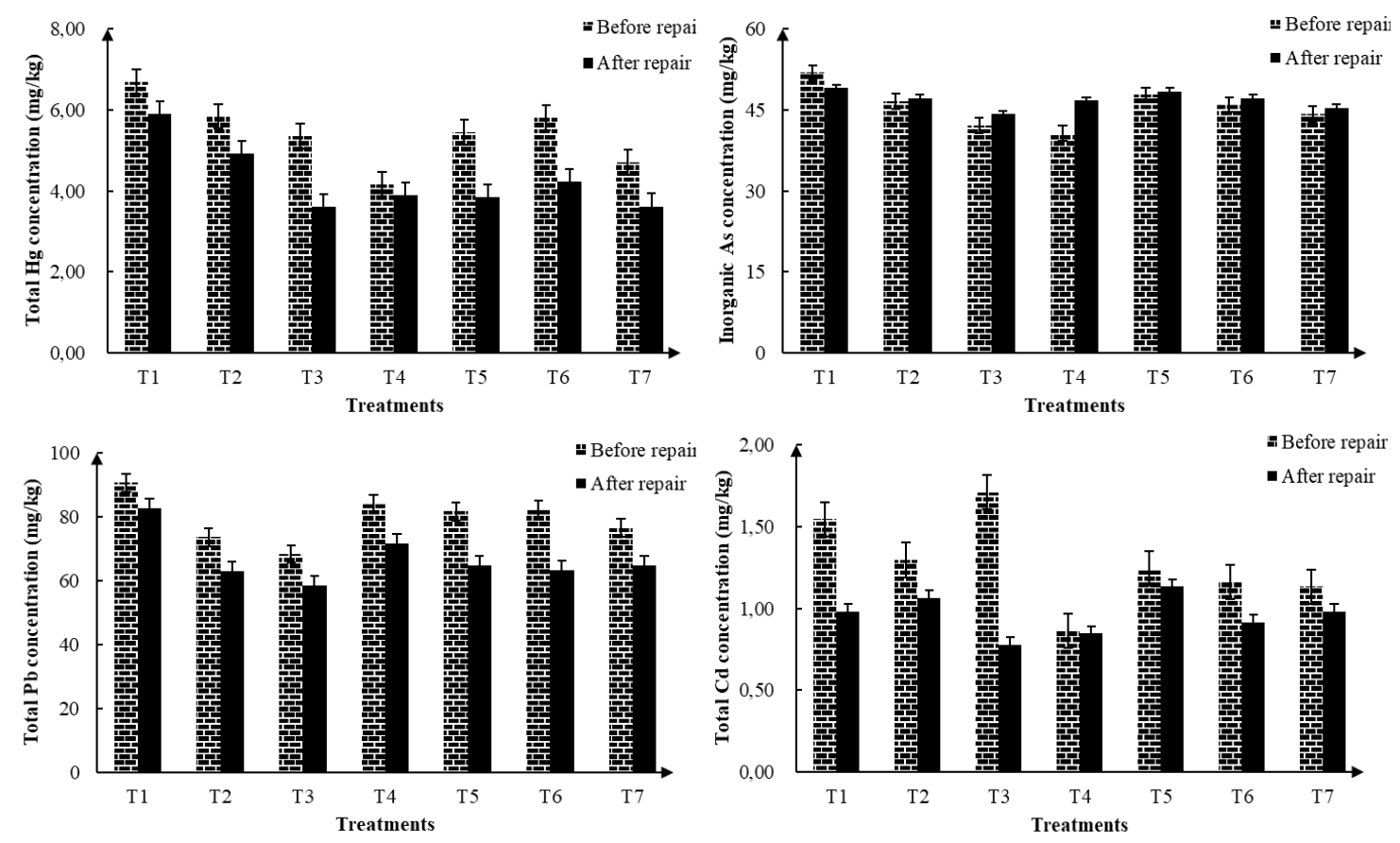

Figure 3. Changes in the total $\mathrm{Hg}, \mathrm{Pb}, \mathrm{Cd}$, and inorganic As content of the soil for the different treatments 
Effect and evaluation of the different remediation treatments on the $\mathrm{Hg}, \mathrm{Pb}, \mathrm{Cd}$, and inorganic As content of spinach

The $\mathrm{Hg}, \mathrm{Pb}, \mathrm{Cd}$ and inorganic As content of the edible parts of spinach after treatments T1-T7 were applied are shown in Table 9 (Aboveground part). As can be seen in Table 9, the average total $\mathrm{Hg}, \mathrm{Cd}$, and inorganic As content of the edible part of the spinach after treatments T1-T7 were applied are 0.360-1.059, 0.790-2.605, and $0.540-1.143 \mathrm{mg} / \mathrm{kg}$, respectively. They are all over the threshold of pollutants in foods according to the National Food Safety Standard (GB 2762-2012). The average total Pb content of the edible part of the spinach after treatments T1-T7 was $0.211-1.321 \mathrm{mg} / \mathrm{kg}$. With the exception that the total Pb content of the edible part of the spinach after T1 was slightly higher than the threshold set by GB 2762-2012, the results of the other groups are all below the threshold of the national standard. Among them, the total $\mathrm{Pb}$ content of the edible part of the spinach after T1 reached $1.321 \mathrm{mg} / \mathrm{kg}$, which is 1.32 times higher than the limit of pollutants set by GB 2762-2012. Combined with the risk index evaluation, except for T5, the risk index HI of the edible part of the spinach after treatments T1-T7 were applied is greater than 10, which indicates that the total $\mathrm{Hg}, \mathrm{Pb}$, $\mathrm{Cd}$ and inorganic As content of the spinach have toxic effects on human health. The HI ranking of the edible parts of the spinach follows the order T1-T7 of T1 > T4 > T6 > $\mathrm{T} 2>\mathrm{T} 3>\mathrm{T} 7>\mathrm{T} 5$.

Table 9. Content and evaluation of the total $\mathrm{Hg}, \mathrm{Pb}, \mathrm{Cd}$, and inorganic As content of the spinach after the different treatments

\begin{tabular}{c|c|c|c|c|c}
\hline Treatment & $\begin{array}{c}\text { Total Hg } \\
\text { content } \\
\text { (mg/kg) }\end{array}$ & $\begin{array}{c}\text { Inorganic As } \\
\text { content } \\
\text { (mg/kg) }\end{array}$ & $\begin{array}{c}\text { Total Pb } \\
\text { content } \\
\text { (mg/kg) }\end{array}$ & $\begin{array}{c}\text { Total Cd } \\
\text { content } \\
(\mathbf{m g} / \mathbf{k g})\end{array}$ & $\begin{array}{c}\text { Hazard index } \\
\text { (HI) }\end{array}$ \\
\hline T1(control group) & $0.759 \pm 0.067$ & $2.452 \pm 0.376$ & $1.321 \pm 0.269$ & $0.783 \pm 0.110$ & 12.99 \\
T2 & $0.737 \pm 0.008$ & $2.322 \pm 0.302$ & $0.584 \pm 0.074$ & $0.872 \pm 0.188$ & 12.12 \\
T3 & $0.468 \pm 0.059$ & $2.508 \pm 0.131$ & $0.451 \pm 0.103$ & $0.908 \pm 0.055$ & 11.97 \\
T4 & $1.059 \pm 0.152$ & $1.923 \pm 0.265$ & $0.593 \pm 0.094$ & $0.965 \pm 0.119$ & 12.60 \\
T5 & $0.482 \pm 0.044$ & $0.790 \pm 0.020$ & $0.527 \pm 0.208$ & $0.759 \pm 0.104$ & 7.82 \\
T6 & $0.360 \pm 0.065$ & $2.219 \pm 0.511$ & $0.211 \pm 0.061$ & $1.143 \pm 0.067$ & 12.23 \\
T7 & $0.851 \pm 0.154$ & $2.605 \pm 0.222$ & $0.338 \pm 0.058$ & $0.540 \pm 0.094$ & 10.57 \\
GB 2762-2012 & 0.01 & 0.5 & 1.0 & 0.2 & -- \\
\hline
\end{tabular}

\section{Discussion}

It is well known that the $\mathrm{pH}$ value is one of the main factors that affects the adsorption of heavy metals. The total $\mathrm{Hg}, \mathrm{Pb}$, and $\mathrm{Cd}$ content of the soil after remediation treatments T2-T7 were applied were lower than those before the remediation, while the inorganic As content of the soil after remediation was slightly higher than that before remediation. This may be due to the increase in the soil $\mathrm{pH}$ caused by the addition of the biochar, which promoted the release of inorganic As into the soil (Hartley et al., 2009). Among the soil properties, the soil $\mathrm{pH}$ value has a significant influence on the solubility and form of the metals in soil and plays a vital role in the form of the metals as well as the solubility, migration, and final bioavailability of the minerals (Zeng et al., 2011). In addition, $\mathrm{pH}$ value also affects the surface charge of the adsorbent and the ionization adsorption (Yu et al., 2013). Xiao et 
al. (2017) pointed out that the degree of the adsorption of the heavy metals onto the biochar is closely related to the acid-base degree of the biochar in addition to the pyrolysis temperature and the ionic strength of the biochar. As the $\mathrm{pH}$ value increases, the adsorption of the heavy metals onto the biochar increases significantly. For example, Rahman and Islam (2009) reported that the adsorption capacity of biochar for $\mathrm{Cu}$ in solution is very low under acidic conditions, only $28.66 \%$. When the $\mathrm{pH}$ value reached 7, the adsorption capacity increased significantly, reaching $83.25 \%$. Kilic et al. (2013) investigated the adsorbtion of $\mathrm{Ni}$ and $\mathrm{Co}$ in an aqueous solution onto almond shell biochar. The results revealed that when the $\mathrm{pH}$ is increased from 2 to 6 , the adsorption capacity of the $\mathrm{Ni}$ and $\mathrm{Co}$ ions increased, and the surface of the adsorbent was negatively charged, which increased the interaction between the $\mathrm{Ni}$ (II) and Co (II) and the binding sites. Zeng et al. (2011) found that under acidic conditions, soluble trivalent $\mathrm{Cr}$ was reduced to pentavalent $\mathrm{Cr}$, and the mobility and effectiveness of $\mathrm{Cr}$ increased with increasing $\mathrm{pH}$. Houben et al. (2013) showed that biochar increased soil $\mathrm{pH}$ and reduced the extractability and bioavailability of the $\mathrm{Cd}, \mathrm{Zn}$, and $\mathrm{Pb}$ in the soil. The positive correlation between the available $\mathrm{Cr}$ and the soil $\mathrm{pH}$ has also been reported in previous studies (Guo et al., 2017). However, several studies have shown that when the $\mathrm{pH}$ exceeds a certain value, the adsorption efficiency of biochar for metal ions decreases, which may be due to the formation of soluble hydroxylation complexes of the metal ions and their competition with the active centers (Sari et al., 2007).

In addition to $\mathrm{pH}$, the organic matter in the soil also affects the availability of the heavy metals. The effect of organic matter on the availability of heavy metals has been widely studied. Studies have shown that as the organic matter content of the soil decreases, the adsorption capacity of the heavy metals in the soil components also decreases (Hettiarachchi et al., 2003; Antoniadis et al., 2008). Bradl (2004) also reported that the organic matter content of the soil is the main characteristic of heavy metal adsorption, and the combination of metal ions and organic matter often reduces the concentration of free heavy metal ions in a soil solution and the toxicity of the heavy metals Abollino et al. (2003). Pichtel et al. (2008) and Gunadasa et al. (2012) determined that as the organic matter content of the soil increases, the $\mathrm{Cd}$ content of the plants grown in the soil significantly decreases. Pichtel and Bradway (2008) also pointed out that the addition of organic fertilizer to the soil significantly reduced the bioavailability of $\mathrm{Cd}$. Bolan et al. (2014) and others found that adding organic modifiers to soil contaminated with heavy metals can reduce the mobility of the heavy metals.

In this study, seven different remediation treatments were investigated to determine their impacts on the $\mathrm{Hg}$, inorganic $\mathrm{As}, \mathrm{Pb}$, and $\mathrm{Cd}$ content of soil and spinach, and their impacts were found to be different. Among them, the risk index of the heavy metals in the spinach after treatments $\mathrm{T} 2-\mathrm{T} 7$ were applied was lower than that of $\mathrm{T} 1$, because no biochar was added to T1, while the other factors, e.g., temperature, climate, and water content, were exactly the same as in treatments T2-T7. The risk index of the heavy metals in the spinach was the lowest after method T5 was applied, and the remediation measure taken in method $\mathrm{T} 5$ was the addition of 3\% cassava stem biochar. The pore diameter of the cassava stem is larger than those of the other types of biochar, which is conducive to the adsorption of heavy metals. However, the $\mathrm{pH}$ value of the soil treated using method T5 was higher after the biochar was added. In addition, 3\% biochar is higher than $1 \%$ biochar, and the application of $3 \%$ cassava stem biochar can more effectively remediate the heavy metal pollution in soil and prevent the migration of 
heavy metal ions into plants. Compared with treatments T3, T5, and T7, the content of the other heavy metals in the soil after the three remediation treatments were applied were significantly lower than the contents before the remediation, except for inorganic As. The risk index of the heavy metals in the spinach after treatments T3, T5, and T7 were applied was lower than that for treatments T2, T4, and T6. This result shows that the adsorption of heavy metals in soil by biochar decreases as the amount of biochar added increases, and it can effectively inhibit heavy metals from entering plants through bioconcentration. The above results show that cassava stem biochar has a better adsorption effect on heavy metals than the other types of biochar, and the application of biochar can not only improve the physical and chemical properties of soil and decrease the contents of heavy metals but also significantly reduce the risk index of spinach, which is worth promoting in future research and production.

\section{Conclusions}

(1) Before remediation, the total $\mathrm{Pb}$ and $\mathrm{Cd}$ content of the soil indicated slight pollution, the inorganic As content indicated moderate pollution, and the total $\mathrm{Hg}$ content indicated extreme pollution. The potential ecological $\mathrm{RI}$ of the total $\mathrm{Hg}, \mathrm{Pb}, \mathrm{Cd}$, and inorganic As was 3014.66, and the pollution level was extremely high, indicating that there was a certain degree of heavy metal pollution in the soil from the collection area (Hg mining area, Xunyang, Ankang).

(2) Compared with the conditions before remediation, the organic matter content and $\mathrm{pH}$ value of the soil after remediation treatments $\mathrm{T} 1-\mathrm{T} 7$ were changed. The $\mathrm{pH}$ values of the soil increased by $0.16-1.10$, indicating that treatments $\mathrm{T} 1-\mathrm{T} 7$ have a certain impact on the physical and chemical properties of the soil.

(3) Compared with the conditions before remediation, after treatments T2-T7 were applied, the inorganic As contents of the soil increased by $0.7-6.0 \mathrm{mg} / \mathrm{kg}$, and after treatments $\mathrm{T} 1-\mathrm{T} 7$ were applied, the total $\mathrm{Hg}, \mathrm{Cd}$, and $\mathrm{Pb}$ content of the soil decreased by $0.8-1.76 \mathrm{mg} / \mathrm{kg}, 8.0-17.1 \mathrm{mg} / \mathrm{kg}$, and $0.02-0.56 \mathrm{mg} / \mathrm{kg}$, respectively. After T3 was applied, the total $\mathrm{Hg}$ and $\mathrm{Cd}$ contents of the soil decreased by $1.76 \mathrm{mg} / \mathrm{kg}$ and 0.93 $\mathrm{mg} / \mathrm{kg}$, respectively. After T5 was applied, the total $\mathrm{Pb}$ content of the soil decreased the most, i.e., by $17.1 \mathrm{mg} / \mathrm{kg}$.

(4) After treatments T1-T7 were applied, the average total $\mathrm{Hg}, \mathrm{Cd}$ and inorganic As content of the edible part of the spinach were $0.360-1.059,0.540-1.143$ and $0.790-2.605 \mathrm{mg} / \mathrm{kg}$, respectively, which exceeds GB 2762-2012. After method T1, the total $\mathrm{Pb}$ content of the edible part of the spinach was $1.321 \mathrm{mg} / \mathrm{kg}$, which exceeds $\mathrm{GB}$ 2762-2012. The amount of Pb pollutants in the spinach was 1.32 times the limit of GB 2762-2012. In addition, the risk index of the spinach after treatments T1-T7 were applied is greater than 10, which indicates that the crops in the soil collection area (Ankang, Xunyang Hg mining area) are more likely to cause harm to human health, and more attention should be paid to farming in this area.

(5) All in all, biochar can improve soil physical properties and heavy metal content, and significantly reduce the risk index of spinach edible parts, which is worthy of popularization and application. However, in the study, the remediation effect of biochar on heavy metals is not obvious. In the later research, we should focus on the properties of different raw materials and the adsorption mechanism of heavy metals. 
Acknowledgments. Financial support was provided by the Research Project of Shaanxi Provincial Land Engineering Construction Group in China (DJNY2021-18). We thank LetPub (www.letpub.com) for its linguistic assistance during the preparation of this manuscript.

\section{REFERENCES}

[1] Abollino, O., Aceto, M., Malandrino, M., Sarzanini, C., Mentasti, E. (2003): Adsorption of heavy metals on Na-montmorillonite. Effect of $\mathrm{pH}$ and organic substances. - Water Research 37(7): 1619-1627.

[2] Abujabhah, I. S., Bound, S., Doyle, R. B., Bowman, J. P. (2016): Effects of biochar and compost amendments on soil physico-chemical properties and the total community within a temperate agricultural soil. - Applied Soil Ecology 98: 243-253.

[3] Ahmad, M., Rajapaksha, A. U., Lim, J. E., Zhang, M., Bolan, N., Mohan, D., Vithanage, M., Lee, S. S., Ok, Y. S. (2014): Biochar as a sorbent for contaminant management in soil and water: a review. - Chemosphere 99: 19-33.

[4] Antoniadis, V., Robinson, J. S., Alloway, B. J. (2008): Effects of short-term pH fluctuations on cadmium, nickel, lead, and zinc availability to ryegrass in a sewage sludge-amended field. - Chemosphere 71(4): 759-764.

[5] Baiamonte, G., de Pasquale, C., Marsala, V., Cimó, G., Alonzo, G., Crescimanno, G., Conte, P. (2015): Structure alteration of a sandy-clay soil by biochar amendments. Journal of soil \& sediments 15: 816-824.

[6] Bian, R., Joseph, S., Cui, L., Pan, G., Li, L., Liu, X., Zhang, A., Rutlidge, H., Wong, S., Chia, C., Marjo, C., Gong, B., Munroe, P., Donne, S. (2014): A three-year experiment confirms continuous immobilization of cadmium and lead in contaminated paddy field with biochar amendment. - Journal of Hazardous Materials 272: 121-128.

[7] Bolan, N., Kunhikrishnan, A., Thangarajan, R., Kumpiene, J., Park, J., Makino, T., Kirkham, M. B., Scheckel, K. (2014): Remediation of heavy metal(loid)s contaminated soils-to mobilize or to immobilize? - Journal of Hazardous Materials 266: 141-166.

[8] Bradl, H. B. (2004): Adsorption of heavy metal ions on soils and soils constituents. Journal of Colloid \& Interface Science 277(1): 1-18.

[9] Brick, S., Lyutse, S. (2010): Biochar: Assessing the promise and risks to guide US policy. - Natural Resources Defense Council. USA. http://www. nrdc. org/energy/files/biochar_paper.

[10] Cantrell, K. B., Hunt, P. G., Uchimiya, M., Novak, J. M., Ro, K. S. (2012): Impact of pyrolysis temperature and manure source on physicochemical characteristics of biochar. - Bioresource Technology 107: 419-428.

[11] Chen, B., Chen, Z., Lv, S. (2010): A novel magnetic biochar efficiently sorbs organic pollutants and phosphate. - Bioresource Technology 102(2): 716-723.

[12] Choppala, G. K., Bolan, N. S., Megharaj, M., Chen, Z., Naidu, R. (2012): The influence of biochar and black carbon on reduction and bioavailability of chromate in soils. Journal of Environmental Quality 41(4): 1175-1184.

[13] Enders, A., Hanley, K., Whitman, T., Joseph, S., Lehmann, J. (2012): Characterization of biochars to evaluate recalcitrance and agronomic performance. - Bioresource Technology 114: 644-653.

[14] Glaser, B., Lehmann, J., Zech, W. (2002): Ameliorating physical and chemical properties of highly weathered soils in the tropics with charcoal - a review. - Biology \& Fertility of Soils 35: 219-230.

[15] Gunadasa, H., Yapa, P. I., Nissanka, S. P., Perera, S. P. (2012): Remediation of $\mathrm{Pb} / \mathrm{Cd}$ contaminated forest soils by compost and mycorrhizae: will it be a solution to the forest dieback. - In International Conference on Future Environment and Energy 28: 139-144.

[16] Guo, X., Li, H., Chen, H. (2017): The effects of biochar and intercropping on the Cd, Cr and $\mathrm{Zn}$ speciation in soils and plant uptake bymachilus pauhoi. - Bulletin of 
Environmental Contamination \& Toxicology 98(4): 1-8.

[17] Hakanson, L. (1980): An ecological risk index for aquatic pollution control. A sedimentological approach. - Water Research 14(8): 975-1001.

[18] Hartley, W., Dickinson, N. M., Riby, P., Lepp, N. W. (2009): Arsenic mobility in brownfield soils amended with green waste compost or biochar and planted with Miscanthus. - Environmental Pollution 157(10): 2654-2662.

[19] Hernandez-Soriano, M. C., Jimenez-Lopez, J. C. (2012): Effects of soil water content and organic matter addition on the speciation and bioavailability of heavy metals. - Science of Total Environment 423: 55-61.

[20] Hettiarachchi, G. M., Ryan, J. A., Chaney, R. L., La Fleur, C. M. (2003): Sorption and desorption of cadmium by different fractions of biosolids-amended soils. - Journal of Environment Quality 32(5): 1684-1693.

[21] Hossain, M. K., Strezov, V., Chan, K. Y., Nelson, P. F. (2010): Agronomic properties of wastewater sludge biochar and bioavailability of metals in production of cherry tomato (Lycopersicon esculentum). - Chemosphere 78(9): 1167-1171.

[22] Houben, D., Evrard, L., Sonnet, P. (2013): Mobility, bioavailability and pH-dependent leaching of cadmium, zinc and lead in a contaminated soil amended with biochar. Chemosphere 92(11): 1450-1457.

[23] Järup, L. (2003): Hazards of heavy metal contamination. - Brit Med Bull. 68: 167-182.

[24] Kailash, D., Dharmendra, P., Anil, V. (2010): Low cost adsorbents for heavy metal removal from wastewater: a review. - Research Journal of Chemistry \& Environment 14(1): 100-103.

[25] Kılıc, M., Kırbıyık, C., Çepelioğullar, Ö., Pütün, A. E. (2013): Adsorption of heavy metal ions from aqueous solutions by bio-char, a by-product of pyrolysis. - Applied Surface Science 283(15): 856-862.

[26] Klasson, K. T., Uchimiya, M., Lima, I. M. (2014): Uncovering surface area and micropores in almond shell biochars by rainwater wash. - Chemosphere 111: 129-134.

[27] Komkiene, J., Baltrenaite, E. (2016): Biochar as adsorbent for removal of heavy metal ions [Cadmium(II), Copper(II), Lead(II), Zinc(II)] from aqueous phase. - International Journal of Environmental Science \& Technology 13(2): 471-482.

[28] Lehmann, J., Joseph, S. (2015): Biochar for Environmental Management: Science, Technology and Implementation. - Science and Technology 25(1): 15801-15811.

[29] Lei, K., Giubilato, E., Critto, A., Pan, H. Y., Lin, C. Y. (2016): Contamination and human health risk of lead in soils around lead/zinc smelting areas in China. - Environmental science and pollution research international 23(13): 13128-13136.

[30] Li, Z. Y., Ma, Z. W., van der Kuijp, T. J., Yuan, Z. W., Huang, L. (2013): A review of soil heavy metal pollution from mines in China: pollution and health risk assessment. Science of Total Environment 468-469: 843-853.

[31] Li, J. F., Li, Y. M., Wu, Y. L., Zheng, M. Y. (2014): A comparison of biochars from lignin, cellulose and wood as the sorbent to an aromatic pollutant. - Journal of Hazardous Materials 280: 450-457.

[32] Liu, Y. X., Lu, H. H., Yang, S. M., Wang, Y. F. (2016): Impacts of biochar addition on rice yield and soil properties in a cold waterlogged paddy for two crop seasons. - Field Crops Research 191: 161-167.

[33] Lu, K. P., Yang, X., Shen, J. J., Robinson, B., Huang, H. G., Liu, D., Bolan, N., Pei, J. C., Wang, H. L. (2014): Effect of bamboo and rice straw biochars on the bioavailability of $\mathrm{Cd}, \mathrm{Cu}, \mathrm{Pb}$ and $\mathrm{Zn}$ to Sedum plumbizincicola. - Agriculture, Ecosystems and Environment 191: 124-132.

[34] MEP (2014): China soil pollution survey communique in Chinese. - Ministry of Environmental Protection (in Chinese).

[35] Nuithitikul, K., Srikhun, S., Hirunpraditkoon, S. (2010): Influences of pyrolysis condition and acid treatment on properties of durian peel-based activated carbon. Bioresource Technology 101(1): 426-429. 
[36] Pan, J. J., Jiang, J., Xu, R. K. (2014): Removal of Cr (VI) from aqueous solutions by $\mathrm{Na}_{2} \mathrm{SO}_{3} / \mathrm{FeSO}_{4}$ combined with peanut straw biochar. - Chemosphere 101: 71-76.

[37] Pichtel, J., Bradway, D. J. (2008): Conventional crops and organic amendments for $\mathrm{Pb}$, $\mathrm{Cd}$ and $\mathrm{Zn}$ treatment at a severely contaminated site. - Bioresource Technology 99(5): 1242-1251.

[38] Rahman, M. S., Islam, M. R. (2009): Effects of pH on isotherms modeling for $\mathrm{Cu}$ (II) ions adsorption using maple wood sawdust. - Chemical Engineering Journal 149(1-3): 273-280.

[39] Reuben, A., Caspi, A., Belsky, D. W., Broadbent, J., Harrington, H., Sugden, K., Houts, R. M., Ramrakha, S., Poulton, R., Moffitt, T. E. (2017): Association of childhood blood lead levels with cognitive function and socioeconomic status at age 38 years and with IQ change and socioeconomic mobility between childhood and adulthood. - JAMA 317(12): 1244-1251.

[40] Sarı, A., Tuzen, M., Uluözlü, Ö. D., Soylak, M. (2007): Biosorption of Pb (II) and Ni (II) from aqueous solution by lichen (Cladonia furcata) biomass. - Biochemical Engineering Journal 37(2): 151-158.

[41] Shen, X., Huang, D. Y., Ren, X. F., Zhu, H. H., Wang, S., Xu, C., He, Y. B., Luo, Z. C., $\mathrm{Zhu}, \mathrm{Q}$. H. (2016): Phytoavailability of $\mathrm{Cd}$ and $\mathrm{Pb}$ in crop straw biochar-amended soil is related to the heavy metal content of both biochar and soil. - Journal of Environmental Management 168: 245-251.

[42] Shi, T., Liu, Y., Zhang, L., Hao, L., Gao, Z. (2014): Burning in agricultural landscapes: an emerging natural and human issue in China. - Landscape Ecology 29(10): 1785-1798.

[43] Singh, B. P., Cowie, A. L., Smernik, R. J. (2012): Biochar carbon stability in a clayey soil as a function of feedstock and pyrolysis temperature. - Environmental Science \& Technology 46: 11770-11778.

[44] Sun, K., Keiluweit, M., Kleber, M., Pan, Z., Xing, B. (2011): Sorption of fluorinated herbicides to plant biomass-derived biochars as a function of molecular structure. Bioresource Technology 102(21): 9897-9903.

[45] Tang, J., Zhu, W., Kookana, R., Katayama, A. (2013): Characteristics of biochar and its application in remediation of contaminated soil. - Journal of Bioence \& Bioengineering 116(6): 653-659.

[46] Titirici, M. M., Thomas, A., Yu, S. H., Müller, J-O., Antonietti, M. (2007): A direct synthesis of mesoporous carbons with bicontinuous pore morphology from crude plant material by hydrothermal carbonization. - Chemistry of Materials 19(17): 4205-4212.

[47] Tóth, G., Hermann, T., Szatmári, G., Pásztor, L. (2016): Maps of heavy metals in the soils of the European Union and proposed priority areas for detailed assessment. Science of Total Environment 565: 1054-1062.

[48] Van Zwieten, L., Singh, B. P., Joseph, S. D., Kimber, S., Cowie, A. L. (2009): Biochar and emission of non- $\mathrm{CO}_{2}$ greenhouse gases from soil. - In: Lehmann, J., Joseph, S. (eds.) Biochar for environmental management science and technology, pp. 227-249.

[49] Wang, N., Han, J. C., Wei, Y., Li, G., Sun, Y. (2019): Potential Ecological Risk and Health Risk Assessment of Heavy Metals and Metalloid in Soil around Xunyang Mining Areas. - Sustainability 11(18): 4828.

[50] Waterlot, C., Bidar, G., Pelfréne, A., Roussel, H., Fourrier, H., Douay, F. (2013): Contamination, fractionation and availability of metals in urban soils in the vicinity of former lead and zinc smelters. - Pedosphere 23(2): 143-159.

[51] Wei, M., Chen, J., Wang, X. (2016): Removal of arsenic and cadmium with sequential soil washing techniques using $\mathrm{Na}_{2}$ EDTA, oxalic and phosphoric acid: optimization conditions, removal effectiveness and ecological risks. - Chemosphere 156: 252-261.

[52] Woolf, D., Amonette, J. E., Street-Perrott, F. A., Lehmann, J., Joseph, S. (2010): Sustainable biochar to mitigate global climate change. - Nature Communications 1: 56.

[53] Wuana, R. A., Okieimen, F. E. (2011): Heavy metals in contaminated soils: a review of sources, chemistry, risks and best available strategies for remediation. - ISRN Ecology: 
402647.

[54] Xiao, R., Wang, S., Li, R., Wang, J. J., Zhang, Z. (2017): Soil heavy metal contamination and health risks associated with artisanal gold mining in Tongguan, Shaanxi, China. Ecotoxicology and Environmental Safety 141: 17-24.

[55] Xiao, Y., Xue, Y., Gao, F., Mosa, A. (2017): Sorption of heavy metal ions onto crayfish shell biochar: effect of pyrolysis temperature, $\mathrm{pH}$ and ionic strength. - Journal of the Taiwan Institute of Chemical Engineers 80: 114-121.

[56] Yu, J. X., Wang, L. Y., Chi, R. A., Zhang, Y. F., Xu, Z. G., Guo, J. (2013): Competitive adsorption of $\mathrm{Pb}^{2+}$ and $\mathrm{Cd}^{2+}$ on magnetic modified sugarcane bagasse prepared by two simple steps. - Applied Surface Science 268: 163-170.

[57] Zeng, F., Ali, S., Zhang, H., Ouyang, Y., Qiu, B., Wu, F., Zhang, G. (2011): The influence of $\mathrm{pH}$ and organic matter content in paddy soil on heavy metal availability and their uptake by rice plants. - Environmental Pollution 159(1): 84-91.

[58] Zhang, X., Yang, L., Li, Y., Li, H., Wang, W., Ye, B. (2012): Impacts of lead/zinc mining and smelting on the environment and human health in China. - Environmental Monitoring \& Assessment 184(4): 2261-2273.

[59] Zhuang, P., Li, Z. A., Zou, B., Xia, H. P., Wang, G. (2013): Heavy metal contamination in soil and soybean near the Dabaoshan Mine, South China. - Pedosphere 23(3): 298-304. 